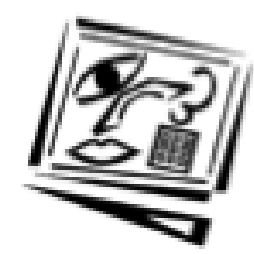

\title{
Designing for learning: What are the essential features of an effective online course?
}

\author{
Allison Brown \\ Murdoch University
}

\section{Introduction}

How do online courses differ from traditional university courses? What are the new learning demands made on students in online courses? Which particular design features optimise the teaching and learning process in an online delivery mode?

These were the questions explored in a collaborative course design project involving an economics lecturer and the instructional designer at Murdoch University. Emerging from the project is the fully online course Economic Thought and Controversy, together with an instructional design template. This template is now being applied to other courses in the discipline with the aim of transferring the whole economics programme to online delivery in 1998.

This paper describes the pedagogical rationale of the design template.

\section{Aims of the design project}

The economics lecturer could see the enormous potential of the WWW as an extremely rich information source. He wanted to use the WWW to create an interconnected knowledge base through the hyperlinking of topics, ideas, and historical events via WWW sites. This was to encourage students to explore the linkages between theory, application, models and paradigms within his own course as well as the interconnections between other courses in economics. He also wanted to take this a step further and create an interdisciplinary knowledge base, by hyperlinking to other disciplines. Thus a student studying macroeconomics would be able to link to courses in economic thought for a deeper understanding of the concepts, while a student studying the theory of supply and demand in a first year economics course could link to courses in sustainable development or sociology to see the environmental and social impact of economics in practice. 
This was seen to be an innovative teaching idea absolutely suited to the medium of the new communications technologies. The instructional design challenge was to help students navigate through such a rich information environment and to help them to intellectually engage with and develop a critical perspective on the material available to them.

The instructional design aim was thus to explore ways in which developments in the communications technologies could be used to enhance teaching and learning in economics.

\section{Early online formats}

Traditionally, teaching in economics has tended to follow the information transmission model, where the lecturer selects a body of knowledge, organises it into a single course package and transmits this to students in a largely one way flow of communication from lecturer to student. The student in this model is often little more than a passive recipient of this information.

Early developments in online course formats tended to be an electronic repackaging of this information transmission methodology, characterised by long scrolling screeds of text presented in a linear format; a continuation of the one-way flow of information from lecturer to students; little navigational structure; and rudimentary levels of interaction ("click to continue"). The underlying premises in this kind of design are that information equates to knowledge and that providing information equates to teaching.

Megarry (1989:50) suggests a different view of the relationship between information and knowledge:

Knowledge is not merely a collection of facts. Although we may be able to memorise isolated undigested facts for a short while at least, meaningful learning demands that we internalise the information: we break it down, digest it and locate it in our pre-existing, highly complex web of interconnected knowledge and ideas, building fresh links and restructuring old ones.

This view is supported by Laurillard (1993) and Jonassen et al (1993) who argue that knowledge is constructed through the active participation of the learner in trying to arrive at and articulate their own personal understandings of new ideas and concepts. Simply providing information, or even access to it, is not enough. Learners need opportunities to reflect on the new material, discuss their tentative understandings with others, actively search for more information to throw light on areas of interest or 
difficulty and build conceptual connections to their existing knowledge base.

How then can the WWW be used to encourage learners to become more active in their learning and to interact and collaborate with others in the learning process?

\section{Hypertext and learner activity}

The most obvious advantage of the WWW is that it allows the publication of a rich array of learning resources. The Murdoch online course Economic Thought and Controversy deliberately seeks to give learners more self directed access to this rich information base. It is designed around a series of topics, readings and activities exploring different schools of economic thought. The important difference is that each topic is presented in a hypertext format thus allowing a degree of learner control as to what information will be accessed and in what order. Relevant links to outside sources are built into the text itself, thus the lecturer's voice is one of many possible voices in the exploration of a topic, and students are no longer confined within disciplinary parameters. Links are made at the point where relevant information interconnects with other information, rather than the traditional add on 'for further information' section at the end of a topic or lecture or set of notes.

Oliver et al (1996) suggest that using hypertext to organise and retrieve information resembles the workings of human memory and cognition far more closely than does the organisational structure of linear text.

Another advantage of using a hypertext approach to presenting information is that the learners can choose for themselves which pathway they want to explore, and in doing so, discover new links for themselves which they are asked to share. Megarry (1989) argues that giving the learner more autonomy in choosing how to interact with the information base makes for more effective learning. This self directed access is an important facet of learner-centred course design and the WWW facilitates immediate access at the point of need. It also enables students to self pace, either exploring issues about a topic of interest more deeply, or spending less time on concepts that are already understood. Students in this environment are no longer "passive learners attempting to mimic what they see and hear from the expert teacher" (Collins \& Berge, 1995:6), but more active participants in the construction of knowledge and meaning. If knowledge building depends upon learners making connections with and between new and old concepts then hypertext is highly suited for facilitating this process. 
File Edit Uiew Go Bookmarks options Directory window

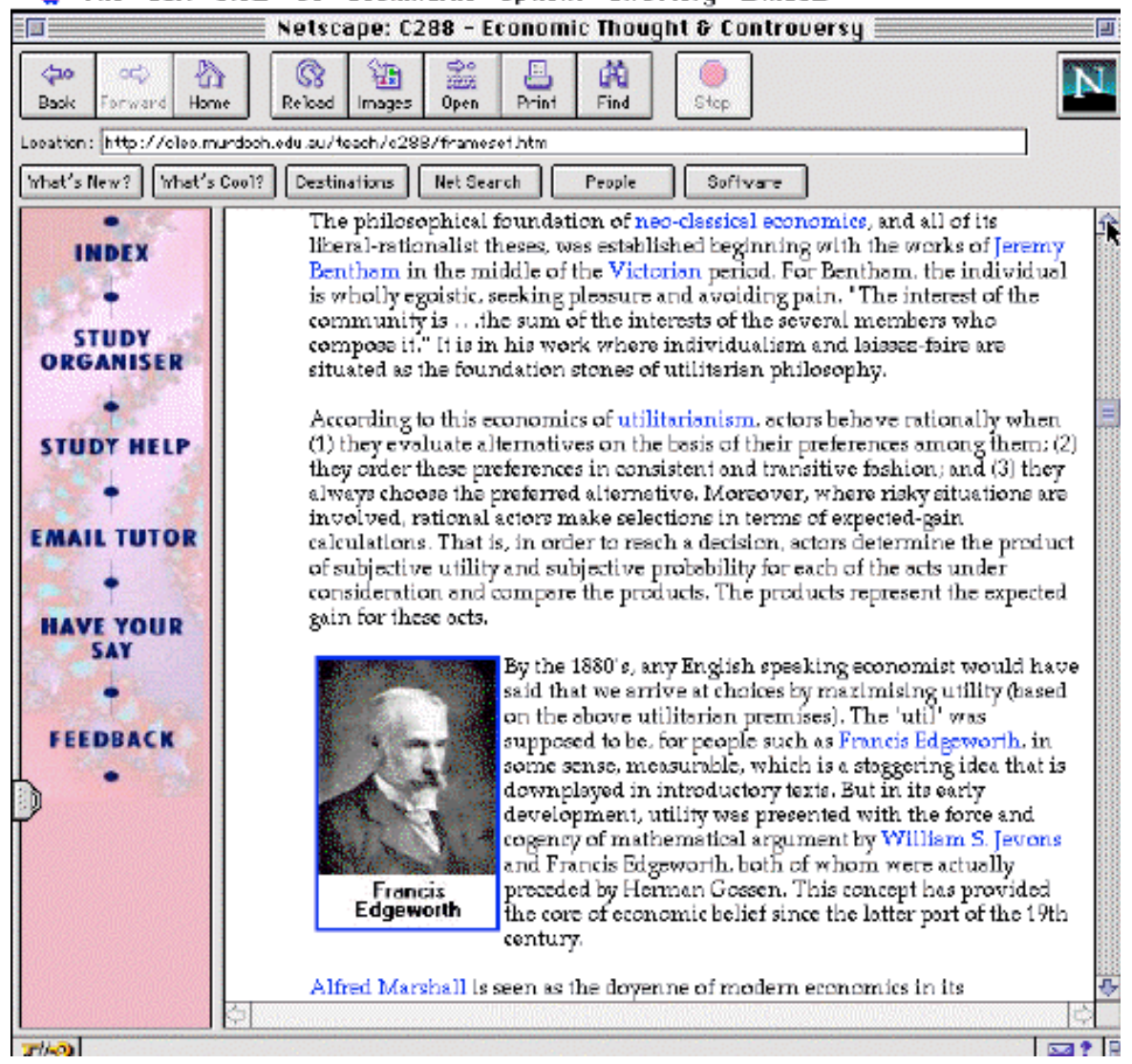

Figure 1: Topic notes presented in hypertext format

\section{Collaborative learning through discussion lists and email}

Having access to a rich information source and the freedom for learners to determine their own pathways through it is only one half of the equation. Students also need to be able to collaborate in the learning process and this is the feature that is most commonly missing in many current online courses.

Harasim (1990) describes peer interaction amongst students as a critical variable in learning. In order to 'come to know', learners need to construct their knowledge by acting upon it, reformulating it, making their own personal interpretation of it, sharing it with others and building upon these ideas and concepts through the reactions and responses of their peers. 
Online education, with its computer mediated communications systems, offers a potentially rich social learning environment which can support and facilitate such active learning collaboration.

Collaborative learning is supported in Economic Thought and Controversy by the inclusion of the "Discussion List" facility. The discussion list is fully automated for ease of use and all members of the online class receive all the messages posted there. The discussion list categorises and files the postings by topic and recently developed discussion list software enables a record of threaded messages to be kept. This allows for new comments to be categorised and grouped accordingly for later reference. As the discussion list provides a written transcript of the online discussion, it builds into a further rich resource: a collaboratively built knowledge base about the topics being discussed. Webb (1989), in a message map analysis of interaction patterns in discussion lists, found that students do respond to the messages of others, adding on and building to the ideas proposed.

\section{Advantages of online discussion}

Online discussion has a number of advantages over oral real time discussion. The asynchronous nature of online discussion allows learners to respond at a time that best suits them. It allows students time to reflect on or further research the topic before responding. Hiltz (1986) found that 'time for reflection' was an important factor in learning effectiveness. It also allows students to seek clarification or help from others immediately the need arises or to learn from whatever discussion is taking place even though they may not themselves have initiated it.

All of these features point to the learner-centredness of the design of Economic Thought and Controversy. User control over a number of learning situations has been facilitated: the time of the interaction, the number of interactions learners choose to make and the time taken to reflect on the issue before a contribution is made.

Online discussion also provides a more egalitarian learning environment. The physical anonymity of the contributors is a great equaliser; more reclusive learners no longer need to struggle for a 'turn to speak', they can make a contribution to the discussion whenever they like with the surety that it will be 'heard' by all class members. Hiltz (1994) found that even 
students for whom English is a second language find the written medium of online discussion to be less threatening in that they can take longer to formulate their positions and can edit and re-edit their responses before posting them to the list. Formative evaluation from students trialing Economic Thought and Controversy tend to support this view:
....I would like to share some thoughts about discussion on this list. First (....) talked a little while back about feeling 'shy' and uncertain about speaking out in class. Personally, I am also shy .....and quite often my messages have been misunderstood, somewhat. However frustrating this is, e-mail has made me far more aware of a need to be careful about what I say and how I say it. This is, I think, both enabling and important - given the potential of the internet as a public forum...Not having to reply instantly to challenges (face-to-face) is quite a bonus for 'shy' people. Also, the time lag on e-mail allows reflection, therefore more informed discussion than usually occurs face to face. I can honestly say that all you who contributed to the on-line education discussion helped me to seriously reconsider a very narrow, uninformed point of view.

The text based nature of online discussion also has a significant impact on knowledge building. The connections between writing and thinking explored in the 60s by language theorists such as Vygotsky (1962) continue to have relevance in this new medium and lend insights into the way in which written online discussion can contribute to the construction of meaning. They argue that it is through the actual process of writing our thoughts and working them over that we really come to understand. The written record allows for revision and encourages self reflection and these are important learning strategies for developing an understanding of new concepts.

In evaluating online courses Harasim (1987) found learners identified the following aspects of online education as beneficial: the increased interaction in terms of both quantity and intensity; better access to group knowledge and support; a more democratic learning environment; convenience of access and increased motivation.

\section{Instructional design to encourage active learning and collaboration}

In the course Economic Thought and Controversy, a conscious part of the design was to include a discussion related to each topic of the course. Rather than just provide this discussion list facility and hope that students might use it and start talking to each other, students are asked to take part in the discussion and to refer to their readings to substantiate their contributions. 
HAVE YOUR SAY!

Think about the following topic, look at relevant readings, and then post your comments or responses to the discussion list

Discussion List Topic 2

With increasing specialisation also comes increasing ignorance. The replacement of 'political economy' with economics may have signalled the discipline's death knell.

Figure 2: Structured use of the discussion list facility.

The discussion topics themselves were deliberately controversial to stimulate engagement by participants and to encourage learners to question their own understanding and to seek more information or clarification from others.

Active learning is further encouraged in this design by the inclusion of learner activities in each topic of the course:

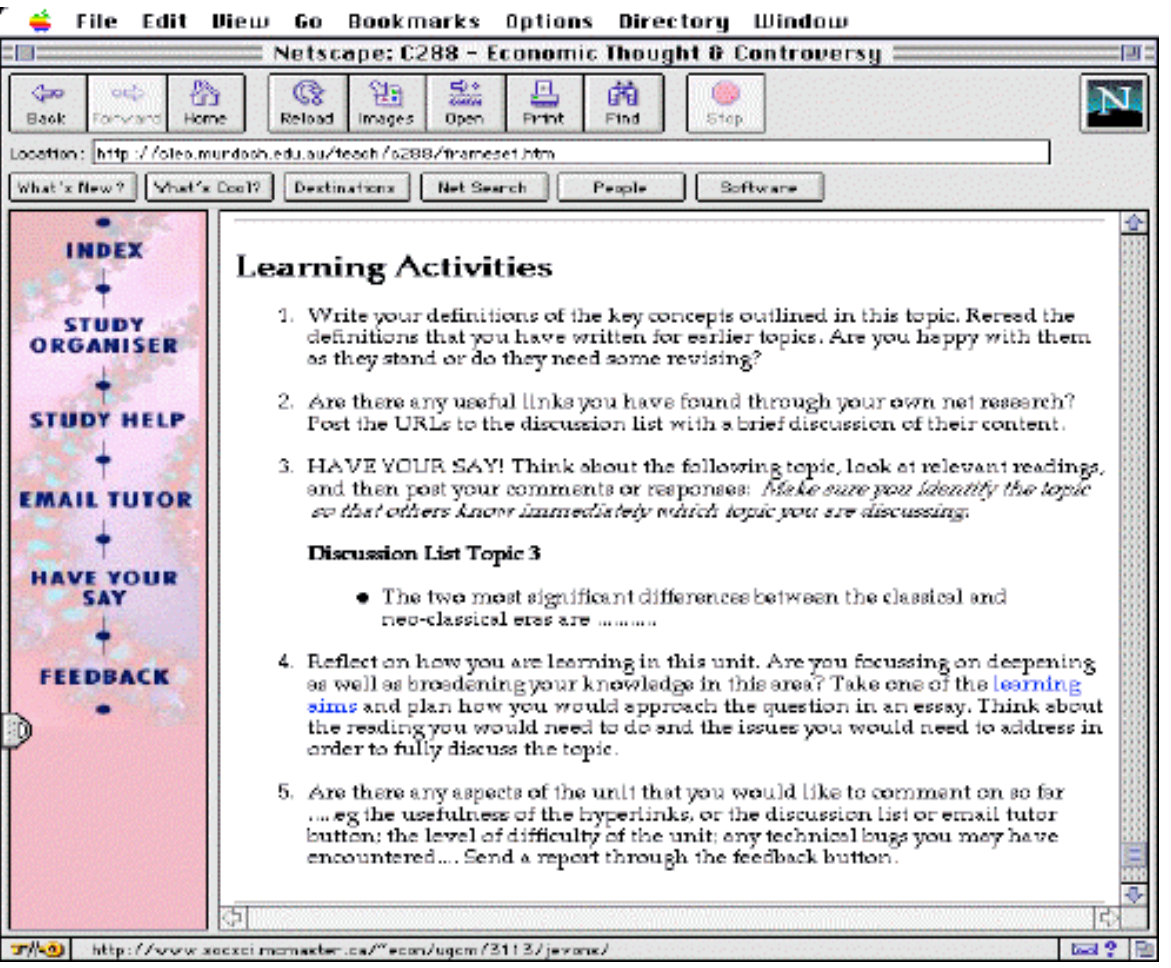

Figure 3: Sample structured learning activities

These activities are non-assessable and are included as aids to learning. They encourage learners to act on the information in some way: putting 
ideas into written form; drawing ideas together and analysing them; interacting with others to further develop ideas. Students can choose how much time to give to these activities. Lockwood's research into self directed activities (1992) found that learning effectiveness improved if these were included in distance education courses. The learning activities included in Economic Thought and Controversy were designed to help learners to develop cognitive learning strategies. Students are encouraged to keep learning journals, to develop concept maps and to access resources for help with developing learning skills.

层 File Edit Diew Go Bookmarks Options Directory Window

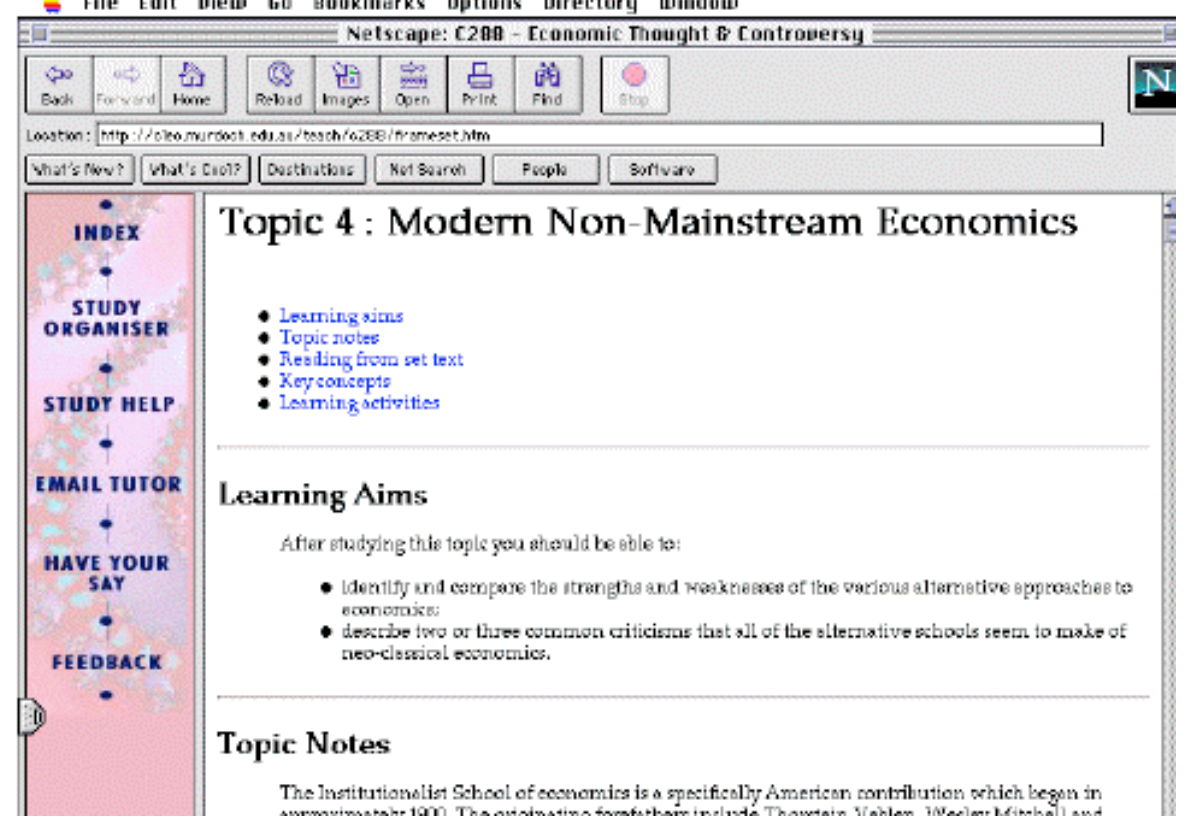

Figure 4: Fixed left hand navigation bar constant on every screen

\section{Interface design}

The ultimate usefulness of hypertext, computer mediated communications systems and cognitive learning strategies as described in this paper depend on an appropriate interface design to enable trouble free and easy access to these features. The interface design must provide ease of navigation, a sense of human interaction, and helpfulness and responsiveness to the needs of learners studying in an information rich, self directed medium. 
Learners need to feel confident that they know where they are at any one point in the course and that they can easily make contact with others as the need arises.

With these specifications in mind, the interface for Economic Thought and Controversy was designed in a table format with a navigation bar as a fixed constant in the left hand table, and a larger scrollable right hand table containing the hyperlinked economics topics. The navigation bar appears on every screen in the same place, no matter which hyperlinks the student chooses to follow in the right hand table. Thus the common problem of getting lost in the hypertext web is overcome with the fixed navigation bar.

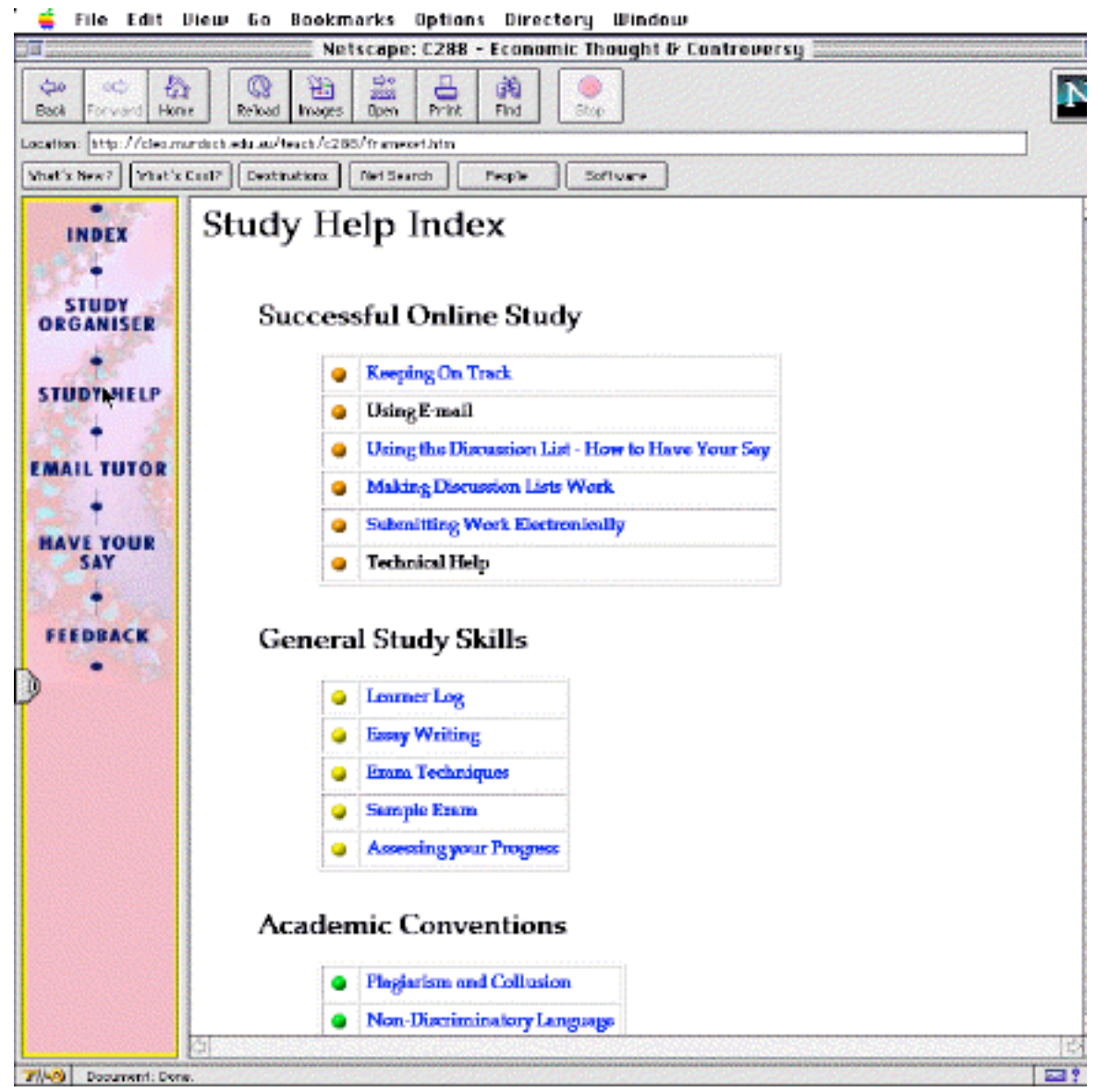

Figure 6: Study help menu 
The Index Button on the navigation bar allows students to navigate their way throughout the entire course. They can access an entire overview of the course and check on their progress through it with the Study Organiser Button. The study organiser helps students to develop an appropriate timetable for study and helps them to stay on track.

The Study Help Button provides immediate online assistance with essay writing, making contributions to discussion lists, referencing, preparing for examinations, technical help, using email etc. Students can access this site at the point of need.

In addition, hyperlinks to the Study Help Button are made at appropriate parts of the course, for example, taking part in the first discussion topic, or when an essay is due.

5. Start thinking about your essay. Look over the essay topics and analyse the questions. Identify the initial reading that you will need to do and put aside time to pursue this reading.

You can find helpful information on essay writing in the Study Help button.

Figure 7: Additional in-course hyperlinks to study help

Should students have particular learning problems that can't be resolved through the Study Help section or on the discussion list with their classmates, they are able to contact their tutor at any time, through the Email Tutor Button. This provides a fully automated screen set up with the tutor's email address and space for the message to by typed. Any email sent to the tutor is private. The tutor email facility helps to establish a learning environment that is helpful, responsive and most importantly, human.

The inclusion of the tutor on the navigation bar helps to remind students that they have not been "abandoned".

The role of the teacher in an online environment is radically different to more traditional teacher-learner relationships. Once teachers have completed the syllabus and instructional design of the online course their role is then to observe, monitor, facilitate and provide information as appropriate, not to deliver a course in a fixed and rigid one-way format.

The Discussion List facility, 'Have Your Say!' is also located on the navigation bar to give prominence to its importance to learning in the course and to enable learners to access it no matter where they are in the 
topics. Should learners need clarification of any concept they come across in the hypertext topics they can immediately send a message to the discussion list asking for peer feedback. They can also quickly and easily share information about any new WWW sites they have discovered by clicking on the discussion list facility no matter where their hyperlinked searches take them.

Both trouble shooting and formative evaluation of the course is facilitated by the Feedback Button in the navigation bar. Through this facility students are encouraged to make comments on any aspect of the course - the usefulness of the learning activities, the appropriateness of the assessment, the usefulness of the readings, any technical problems with the site and access to it, at the immediate time the point occurs to them. The feedback in this online format goes directly to the course coordinator and provides important data on what works well in the course and what doesn't, both in terms of content and technology. It also means that problems can be rectified during the current delivery of the course rather than in subsequent courses as is the case with printed course materials.

\section{Conclusion}

Three central design features for effective online delivery were identified in this project: hypertext; active and collaborative learning; and learnercentredness. The hypertextual organisation of information in the discipline is essential for self directed learning and encourages students to take an active approach to their learning. Collaborative learning by means of the new computer mediated communications systems can extend and support active, purposeful learning. The interface design is sensitive to learner needs and links all the elements in a coherent, meaningful and helpful way for the students.

The approach to online instructional design outlined here provides a rich learning experience in a personalised supportive framework. At the same time it promotes self discipline and requires students to take a more active approach to their learning. It is more important than ever in this new information age that we develop learners who are able to locate appropriate information, make meaning of it, critique it and share their understandings with others.

\section{Acknowledgments}

The economics course discussed in this paper - Economic Thought and Controversy - was written by Herb Thompson, Associate Professor of Economics, Murdoch University, Perth, Western Australia. hthompso@central.murdoch.edu.au 
The course can be viewed at: http://cleo.murdoch.edu.au/teach/c288/

Thanks also to Nicky Taylor, research student at Murdoch University for access to preliminary evaluation data.

\title{
References
}

Berge, Z. L. and Collins, M. P. (eds) (1995). Computer mediated communication and the online classroom. Higher Education Vol II. New Jersey: Hampton Press Inc.

Harasim, L. (1987). Teaching and learning online: Issues in designing computermediated graduate courses. Canadian Journal of Educational Communications, 16(2), 117-135.

Harasim, L. (1990). Online education: Perspectives on a new environment. New York: Praeger Publishers.

Hiltz, S. R. (1986). The "virtual classroom": Using computer mediated communication for university teaching. Journal of Communication, 36(2), 95104.

Hiltz, S. T. (1994). The virtual classroom: Learning without limits via computer networks. Human-Computer Interaction Series. Norwood, NJ: Ablex Publishing Corp.

Jonassen, D. H., Duffy, T. M. and Lowyck, J. (eds) (1993). Designing environments for constructive learning. NATO ASI Series, Series F: Computer and Systems Sciences, Vol 105. Heidleberg, Germany: Springer-Verlag.

Laurillard, D. (1993). Rethinking university teaching: A framework for the effective use of educational technology. London: Routledge.

Lockwood, F. (1992). Activities in self instructional texts . London: Kogan Page.

Megarry, J. (1989). Hypertext and compact discs: The challenge of multimedia learning. In C. Bell, J. Davies and R. Winders (eds), Promoting Learning: Aspects of Educational and Training Technology XXII. London: Kogan Page.

Oliver, R., Herrington, J. and Omari, A. (1996). Creating effective instructional materials for the World Wide Web. http://www.scu.edu.au/ausweb96/educn/oliver

Vygotsky, L. S. (1962). Thought and Language. Cambridge MA: MIT Press.

Webb, N. (1989). Peer interaction and learning in small groups. International Journal of Educational Research, 13(1), 21-29.

\author{
Allison Brown, Instructional Designer \\ Teaching and Learning Centre \\ Murdoch University \\ Murdoch WA 6150 Australia \\ email: a_brown@cleo.murdoch.edu.au
}

